\title{
Renal artery injury during lateral transpsoas interbody fusion: case report
}

\author{
Daniel J. Blizzard, MD, MS, ${ }^{1}$ Michael A. Gallizzi, MD, MS, ${ }^{1}$ Robert E. Isaacs, MD, ${ }^{2}$ and \\ Christopher R. Brown, MD1
}

\begin{abstract}
${ }^{1}$ Department of Orthopaedic Surgery; and 2Division of Neurological Surgery, Department of Surgery, Duke University Medical Center, Durham, North Carolina
\end{abstract}

\begin{abstract}
Lateral interbody fusion (LIF) via the retroperitoneal transpsoas approach is an increasingly popular, minimally invasive technique for interbody fusion in the thoracolumbar spine that avoids many of the complications of traditional anterior and transforaminal approaches. Renal vascular injury has been cited as a potential risk in LIF, but little has been documented in the literature regarding the etiology of this injury. The authors discuss a case of an intraoperative complication of renal artery injury during LIF. A 42-year-old woman underwent staged T12-L5 LIF in the left lateral decubitus position, and L5-S1 anterior lumbar interbody fusion, followed 3 days later by T12-S1 posterior instrumentation for idiopathic scoliosis with radiculopathy refractory to conservative management. After placement of the T12-L1 cage, the retractor was released and significant bleeding was encountered during its removal. Immediate consultation with the vascular team was obtained, and hemostasis was achieved with vascular clips. The patient was stabilized, and the remainder of the procedure was performed without complication. On postoperative CT imaging, the patient was found to have a supernumerary left renal artery with complete occlusion of the superior left renal artery, causing infarction of approximately $75 \%$ of the kidney. There was no increase in creatinine level immediately postoperatively or at the 3-month follow-up. Renal visceral and vascular injuries are known risks with LIF, with potentially devastating consequences. The retroperitoneal transpsoas approach for LIF in the superior lumbar spine requires a thorough knowledge of renal visceral and vascular anatomy. Supernumerary renal arteries occur in $25 \%-40 \%$ of the population and occur most frequently on the left and superior to the usual renal artery trunk. These arteries can vary in number, position, and course from the aorta and position relative to the usual renal artery trunk. Understanding of renal anatomy and the potential variability of the renal vasculature is essential to prevent iatrogenic injury.
\end{abstract}

http://thejns.org/doi/abs/10.3171/2016.2.SPINE15785

KEY WORDS lateral interbody fusion; LIF; retroperitoneal; vascular injury; renal artery; renal vein; lumbar

$\mathrm{L}$ ATERAL interbody fusion (LIF) via the retroperitoneal transpsoas approach is an increasingly popular, minimally invasive technique for interbody fusion in the lumbar and thoracic spine. ${ }^{4,5}$ This technique avoids many of the complications of traditional anterior and transforaminal approaches, including visceral and major vessel injury. However, LIF is associated with several specific risks, including postoperative hip flexion weakness and genitofemoral or lumbar plexus nerve injury as well as the inherent risk of any vertebral arthrodesis surgery: superficial or subfascial infection, endplate violation, persistent pain, and nonunion. ${ }^{2,3,6,8,12}$ Herein, we describe a case of left renal artery laceration during placement of a cage at T12-L1 during T12-L5 LIF that was successfully identified and treated intraoperatively.

\section{Case Report}

A 42-year-old woman with idiopathic scoliosis treated with bracing as an adolescent presented with chronic, worsening, bilateral lower-extremity radiculopathy refractory to conservative management. She was scheduled for staged T12-L5 LIF, L5-S1 anterior lumbar interbody fusion (ALIF), and T12-S1 posterior instrumentation. The first stage, L1-5 LIF and L5-S1 ALIF, was completed without complication. 
Three days later, the patient returned to the operating room for the second stage. She was placed in the lateral decubitus position with the left side up. Fluoroscopy was used to plan an incision over the T12-L1 disc space. The dissection was carried down to the retroperitoneal space. Sequential dilators created space for the tubular retractor, which was centered over the posterior one-third of the disc. An annulotomy was made with a scalpel, and disc material and endplate cartilage were removed with the aid of pituitary rongeurs and curettes. The right lateral aspect of the disc was released using a Cobb Elevator. A complete discectomy was performed using a series of curettes and pituitary rongeurs. The disc space was distracted and trialed, and an 8-mm lordotic spacer was placed. The tubular retractor was then collapsed. While removing the retractor, significant bleeding was encountered. The incision was extended in-line approximately $2.5 \mathrm{~cm}$ anteriorly and posteriorly, and the source was localized as a renal artery. Pressure was applied, and an emergent vascular surgery consult was obtained. Hemostasis was achieved using multiple large vascular clips. A chest tube was placed to function as a drain in the pleural cavity. The lateral wound was then closed with no obvious bleeding. The patient was then repositioned prone and the posterior instrumentation was placed without complication.

On postoperative day (POD) 2, the patient became intermittently febrile. On POD 3, CT angiography was performed, which demonstrated bilateral lung consolidations and multiple left renal infarcts (Figs. 1 and 2). The patient was treated with broad-spectrum antibiotics for suspected hospital-acquired pneumonia. No interventions were undertaken for her kidney, and her creatinine function remained normal. She continued to improve thereafter and was discharged home on POD 8. At the 2-week and 3-month follow-up visits she continued to do well, with normal creatinine and no sequelae of the renal injury. At the 18-month follow-up, she reported resolution of her radicular pain, and her renal function remained normal.

\section{Discussion}

Although renal visceral and vascular injuries are cited risks for LIF, the incidence and mechanism of these injuries have not been described. Several series collectively accounting for 1026 cases have reported complication rates ranging from $5 \%$ to $25 \%$, but only 2 cases of renal injury have been reported. ${ }^{1-4,11,12}$ Isaacs et al. reported a kidney laceration, and Yuan et al. reported a "nicked renal vein" in a single patient. ${ }^{4,13}$ These injuries were not further detailed.

Renal vasculature is highly variable and can vary in vessel numbers and course..$^{10}$ Accessory arteries, which accompany the main vessel to the hilum, and aberrant arteries, which supply the superior or inferior pole without entering the hilum, occur in approximately $30 \%$ of patients. ${ }^{7,9,10}$

The course of aberrant arteries is unpredictable, and vessels can enter the kidney directly superiorly or even posteriorly, lying directly over the psoas and vertebral body. The retroperitoneal transpsoas approach for LIF requires exposure immediately adjacent to the kidneys and

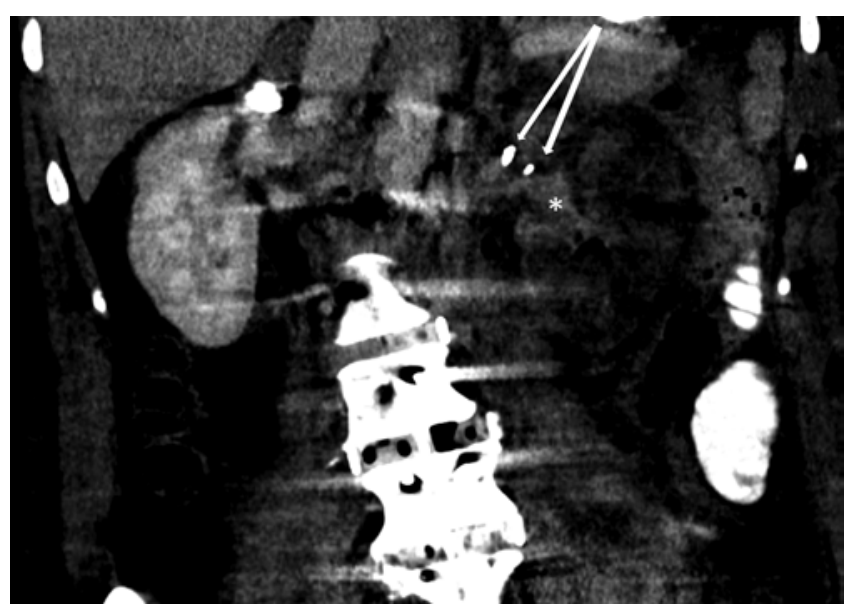

FIG. 1. Coronal CT scan demonstrating vascular clips denoted by arrows occluding the aberrant left renal artery, which entered the left kidney superior and posterior to the main left renal artery denoted by the asterisk.

associated vasculature for low thoracic and high lumbar fusions. During retractor placement, the kidney, paravertebral musculature, and renal vasculature are palpated and partially visualized to determine safe placement. Sequential dilators are used to atraumatically create space for the retractor before it is opened. After cage placement the retractor is collapsed and removed.

In the present case, arterial injury was caused either by interposition of the vessel wall of an aberrant artery between the retractor blades or by direct injury during retractor insertion that was tamponaded when the retractor was opened and only became evident when the retractor blades were closed (Fig. 3). This arterial injury led to infarction of approximately $60 \%$ of the left kidney. The maintenance of normal renal functioning in this case is not surprising as it is well known that kidney donors maintain normal renal functioning after donation. However, a similar vascular injury in a patient with a single kidney or with 2 poorly functioning kidneys could result in ir-

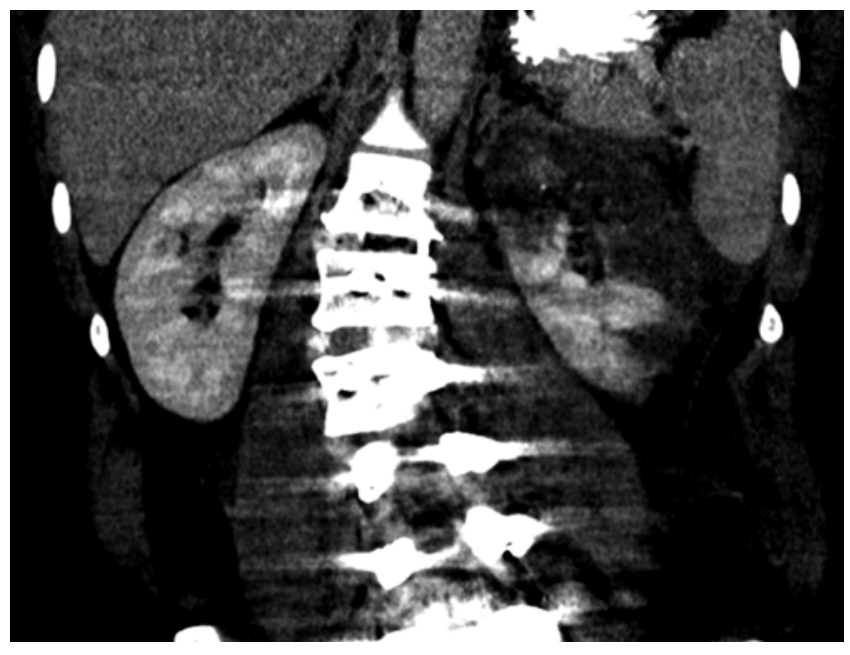

FIG. 2. Coronal CT scan demonstrating ischemia of approximately $75 \%$ of the superior left kidney, but preserved inferior pole supplied by the main left renal artery. 


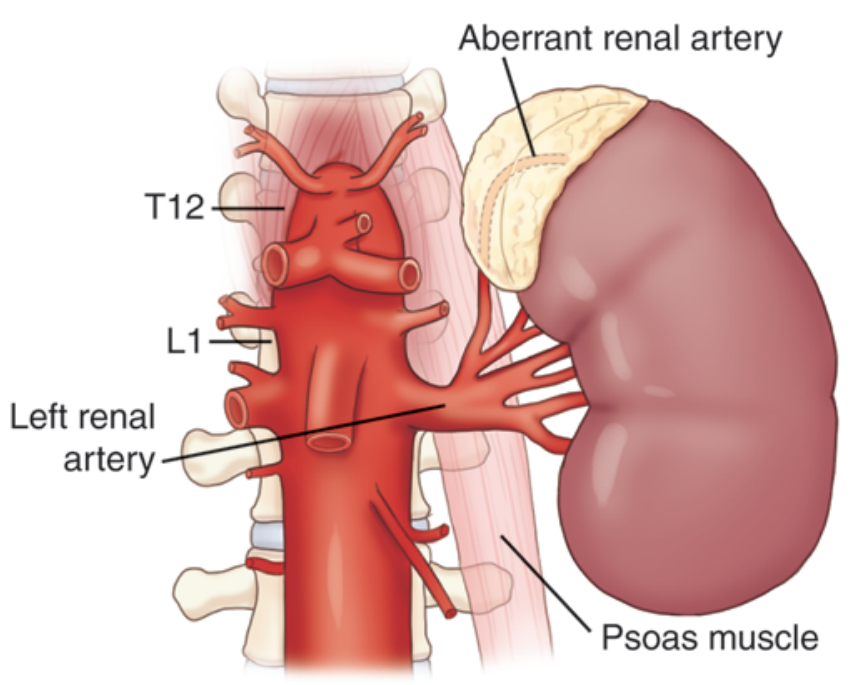

FIG. 3. Illustration depicting the course of the aberrant renal artery from the left renal artery into the left kidney. Copyright Michael Gallizzi. Published with permission. Figure is available in color online only.

reversible renal failure. Accordingly, in patients with an anatomical or physiological single kidney, we recommend a contralateral spinal approach to reduce the risk of injuring the remaining kidney.

Direct visualization of the bleeding site is critical to obtain hemostasis and was achieved in this case with in-line extension of the original horizontal incision. If further exposure is needed, the incision could be extended vertically or in an S-shape as needed. Immediate hemostasis can be obtained with direct pressure or a temporary clamp. Definitive hemostasis should be obtained with a vascular clip or suture ligation. In cases in which the solitary arterial or venous vessel supplying the kidney is injured and vascular surgery is available, direct vessel repair could be attempted. However, the primary goal after the injury is sustained is definitive hemostasis, as renal function can be preserved with a single kidney.

Knowledge of potential anatomical variations is essential when operating in the retroperitoneal space in the thoracolumbar spine, as minimally invasive approaches can preclude direct visualization of neurovascular structures and potential variants. Failure to account for this prior to docking retractors can result in ischemic necrosis of the kidney or possible death if hemostasis cannot be achieved.

\section{References}

1. Formica M, Berjano P, Cavagnaro L, Zanirato A, Piazzolla A, Formica C: Extreme lateral approach to the spine in degenerative and post traumatic lumbar diseases: selection process, results and complications. Eur Spine J 23 (Suppl 6):684-692, 2014

2. Grimm BD, Leas DP, Poletti SC, Johnson DR II: Postoperative complications within the first year after extreme lateral interbody fusion: experience of the first 108 patients. J Spinal Disord Tech [epub ahead of print], 2014

3. Hrabalek L, Adamus M, Gryga A, Wanek T, Tucek P: A comparison of complication rate between anterior and lateral approaches to the lumbar spine. Biomed Pap Med Fac Univ Palacky Olomouc Czech Repub 158:127-132, 2014

4. Isaacs RE, Hyde J, Goodrich JA, Rodgers WB, Phillips FM: A prospective, nonrandomized, multicenter evaluation of extreme lateral interbody fusion for the treatment of adult degenerative scoliosis: perioperative outcomes and complications. Spine (Phila Pa 1976) 35 (26 Suppl):S322-S330, 2010

5. Lazennec JY, Pouzet B, Ramare S, Mora N, Hansen S, Trabelsi R, et al: Anatomic basis of minimal anterior extraperitoneal approach to the lumbar spine. Surg Radiol Anat 21:7-15, 1999

6. Meredith DS, Kepler CK, Huang RC, Hegde VV: Extreme lateral interbody fusion (XLIF) in the thoracic and thoracolumbar spine: technical report and early outcomes. HSS J 9:25-31, 2013

7. Ozkan U, Oğuzkurt L, Tercan F, Kizilkiliç O, Koç Z, Koca $\mathrm{N}$ : Renal artery origins and variations: angiographic evaluation of 855 consecutive patients. Diagn Interv Radiol 12:183-186, 2006

8. Patel VC, Park DK, Herkowitz HN: Lateral transpsoas fusion: indications and outcomes. ScientificWorldJournal 2012:893608, 2012

9. Praveen Kumar M, Suseelamma D, Saritha S, Lingaswamy V: Multiple renal vascular variations. Open Access Sci Rep 1:1-2, 2012

10. Rao TR: Aberrant renal arteries and its clinical significance: a case report. Int J Anat Var 4:37-39, 2011

11. Rodgers WB, Gerber EJ, Patterson J: Intraoperative and early postoperative complications in extreme lateral interbody fusion: an analysis of 600 cases. Spine (Phila Pa 1976) 36:26-32, 2011

12. Youssef JA, McAfee PC, Patty CA, Raley E, DeBauche S, Shucosky E, et al: Minimally invasive surgery: lateral approach interbody fusion: results and review. Spine (Phila Pa 1976) 35 (26 Suppl): $S 302-S 311,2010$

13. Yuan PS, Rowshan K, Verma RB, Miller LE, Block JE: Minimally invasive lateral lumbar interbody fusion with direct psoas visualization. J Orthop Surg 9:20, 2014

\section{Disclosures}

The authors report the following: Dr. Blizzard, consultant for and clinical or research support for the study described from NuVasive Inc.; Dr. Gallizzi, consultant for Arthrex Inc. and Acuity; Dr. Isaacs, consultant for and grants, contracts, and royalties from NuVasive Inc.; and Dr. Brown, consultant for and grants and payments for lectures and royalties from NuVasive Inc.

\section{Author Contributions}

Conception and design: all authors. Acquisition of data: Blizzard. Drafting the article: all authors. Critically revising the article: all authors. Approved the final version of the manuscript on behalf of all authors: Blizzard. Administrative/technical/material support: Blizzard. Study supervision: Isaacs, Brown.

\section{Supplemental Information}

\section{Previous Presentations}

This work was presented at the 8th Annual SOLAS Research Meeting, April 17-19, 2015, in San Diego, California.

\section{Correspondence}

Daniel J. Blizzard, Department of Orthopaedic Surgery, Duke University Medical Center, DUMC Box 3000, Durham, NC 27710.email: daniel.blizzard@duke.edu. 